\title{
Multiobjective Optimization Model for Sustainable Waste Management Network Design
}

\author{
Sun Olapiriyakul $\mathbb{D}^{D}$, Warut Pannakkong $\mathbb{D}$, Warith Kachapanya, and Stefano Starita
}

School of Manufacturing Systems and Mechanical Engineering, Sirindhorn International Institute of Technology, Thammasat University, Pathum Thani 12121, Thailand

Correspondence should be addressed to Stefano Starita; stefano@siit.tu.ac.th

Received 14 December 2018; Revised 11 March 2019; Accepted 14 April 2019; Published 13 May 2019

Guest Editor: Jesica de Armas

Copyright (c) 2019 Sun Olapiriyakul et al. This is an open access article distributed under the Creative Commons Attribution License, which permits unrestricted use, distribution, and reproduction in any medium, provided the original work is properly cited.

Inefficient or poorly planned waste management systems are a burden to society and economy. For example, excessively long waste transportation routes can have a negative impact on a large share of the population. This is exacerbated by the rapid urbanization happening worldwide and in developing countries. Sustainability issues should be accounted for at every stage of decision making, from strategic to daily operations. In this paper, we propose a multiobjective optimization model to design a cost-effective waste management supply chain, while considering sustainability issues such as land-use and public health impacts. The model is applied to a case study in Pathum Thani (Thailand) to provide managerial insights.

\section{Introduction}

An unsanitary and inefficient municipal solid waste management (MSWM) system has long been a challenging issue to overcome. An inadequate waste management budget and the lack of public participation in waste segregation at the source are among the leading causes for the long-term accumulation of uncollected and improperly disposed of solid wastes in developing countries. In urban areas, unsanitary disposal sites are generally more problematic, considering the limited land availability and the need to attain adequate waste disposal capacity to serve a rapidly growing population. The risk of exposure to contaminants emitted from solid waste disposal is also more pronounced for urban residents. First, this is due to the problem of waste disposal capacity shortage, caused by a lack of land suitable for solid waste receptacles or a delay in building sufficient capacity. Waste flows beyond manageable capacity are among the causes of the uncontrolled release of leachates and gases, which can lead to the formation of strong unpleasant odors and spontaneous fires. Second, in an urban context, expanding the existing disposal facilities or locating new ones has to be made in the vicinity of densely populated areas. The release of hazardous constituents from disposal and transport operations can impose substantial environmental stress on the surrounding communities, especially for centralized MSWM systems [1]. The neighboring population has to deal with the immediate impacts, such as uncleanliness, odors, and inadequate air quality. The long-term impacts of unsanitary MSWM practices on the local population include various health risks [2] and decreased environmental quality [3].

Previous studies highlight the fact that in developing countries MSWM results in decreasing property values [4] and imposes an additional financial burden on the local population in terms of higher sanitation fees [5]. Consequently, a disproportionate environmental impact is an increasingly important issue in MSWM planning. To resolve this issue, environmental justice must be added as one of the strategic goals to be achieved. The principles of environmental justice, in this case, refer to the idea that all communities must be protected from excessive or disproportionate environmental stressors. The level of environmental stressors experienced by communities needs to be evaluated. Whenever possible, the capacity of each community to tolerate unfavorable environmental impacts should be considered.

Aside from disproportionate impacts and justice concerns, the negative externalities of MSWM can also impede the development of desired social aspects such as strong community social cohesion and efficient youth development [6]. The waste management literature [7] also reveals that 
environmental problems of waste management generate a number of social issues, such as those related to employment opportunities [8], unsanitary working conditions [9], and community satisfaction [10]. Attempts to offset these issues usually require significant spending on improving sanitary infrastructure and services. Such financial needs can ultimately leave communities with an insufficient sanitary budget and inability to properly collect and dispose of municipal solid wastes, leading to a vicious cycle of decline in local public health and environmental conditions. Therefore, a sustainable MSWN requires that significant economic, environmental, and social issues be integrated into the strategic decision-making processes.

The successful establishment of sustainable MSWM is dependent on the network design and transportation planning stage. Environmentally benign site selection requires a careful land suitability analysis. The potential interactions of disposal sites with local communities and existing geographical, hydrological, and socioeconomic parameters need to be taken into account. For example, in Thailand, there is a rigorous protocol for solid waste disposal site selection. However, a large number of disposal sites are still located in environmentally sensitive areas. Due to the rapid and unplanned urban growth in many cities, some disposal sites, which were originally in suitable vacant land areas, are now in close proximity to rapidly urbanizing areas. Under the current MSWM situation, the number of affected communities is only expected to rise in the near future. Local governments will also expend a great deal of effort to cope with strong public opposition, should any future solid waste disposal siting or expansion decision be taken. To sum up, a sustainable MSWM requires the development of network design approaches to help in resolving the following MSWM challenges:

(i) finding suitable land for waste disposal,

(ii) public health impacts caused by the operation of MSWM facilities and waste transport,

(iii) lack of land-use planning for MSWM,

(iv) environmental justice and disproportionate environmental impacts on nearby communities.

The remainder of the paper is organized as follows: Section 2 provides a review of the relevant literature. Section 3 introduces a mixed-integer multiobjective program to design a sustainable supply chain for waste management. A case study in Pathum Thani (Thailand) province is analyzed in Section 4. Finally, the conclusion and future research directions are discussed in Section 5.

\section{Background}

This section provides a literature review to gain an insight into the research trends in sustainable MSWM design. We focus on three broad categories: sustainable supply chain network design (SCND), solid waste management, and environmental justice. Results are summarized in a Venn diagram in Figure 1. The diagram reveals that each research field has received

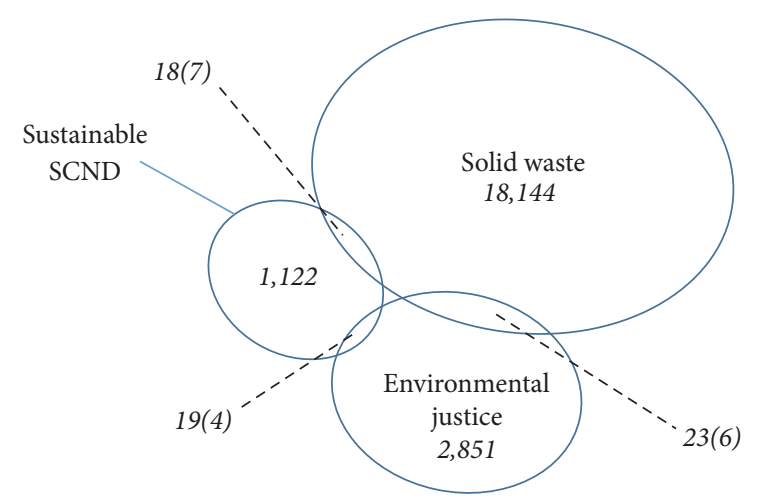

FIGURE 1: Relevant research areas.

considerable attention over the years. There are some pairwise overlaps. However, to the best of our knowledge, no research paper has studied the problem incorporating the three issues at the same time.

Despite a growing research interest in sustainable supply chain management and environmental justice, there is still limited consideration of environmental justice issues in the sustainable SCND literature. Past studies combine equality and justice issues with the environmental and social dimensions. Moura et al. [11] incorporate environmental justice aspects into a biobjective transportation network design model while addressing the (three pillars of) sustainability. Their model uses a restrictive constraint that protects the surrounding communities from being overly burdened with noise and air pollution. The motorists cost of increased travel time due to the congestion effects of the transport network is regarded as the social impact metric. Constraints are imposed to achieve a network design with desired environmental justice levels. There are also previous sustainable SCND studies that investigate social justice issues. These papers generally aim to minimize the inequality in accessing public services and in the quality-of-life improvement opportunities. An SCND study by Ferguson et al. [12] shows how to incorporate social equality into a transit service design problem. They aim to minimize the variation in the level of access to basic amenities provided by the designed transit system. Jafari et al. [13] propose a sustainable SCND model for textile industries, with the aim of promoting social justice by maximizing the employment level in different geographical areas. Despite the increased research efforts, there are still social justice issues that need to be translated into a welldefined optimization problem. Manaugh et al. [14] point out social justice issues and measures that can potentially be incorporated into urban transport planning. These issues are related to the disproportionate accessibility of transport service among different groups of people. Oswald Beiler and Mohammed [15] address many demographic, socialeconomic, and location-based factors that can be considered in developing transportation justice metrics and frameworks.

The topic of solid waste management has been studied in depth due to the steadily growing urban population and consequent waste generation. Life-cycle environmental impacts of various MSWM systems have been explored 
extensively as reviewed by Bernstad Saraiva et al., 2018 [16]. Also, a number of economic, environmental, and social performance indicators for MSWM have been proposed by researchers as addressed by Rodrigues et al., 2018 [17]. However, most of sustainable SCND studies are related to industrial applications. The strategic planning of MSWM infrastructures and transport network has been confined to the analysis of infrastructure investment, operating expenses, and economic viability. For instance, Zhang et al. [18] develop an optimization model to minimize the costs of inventory, transportation, and disposal of MSWM. In their study, an interval programming approach is employed to deal with uncertainties of MSWM planning parameters. Toso and Alem [19] propose a deterministic and stochastic capacitated facility location model to determine the optimal location planning design for recycling urban solid wastes. Their model solely focuses on minimizing the overall costs having budget constraints. Just recently more attention is being given to MSWM planning problems looking beyond economic feasibility to add the sustainability perspective. A network design study by Inghels et al. [20] evaluates the financial viability of using multimodal transportation to reduce the carbon emissions and social impact of MSWM. Their model evaluates the societal cost burden associated with different transportation modes, measured as the sum of disturbance effects on nearby residents. The effects include accidents, noise, air pollution, congestion, and construction of transport infrastructure. Xu et al. [21] propose a SCND model for the reverse logistic supply chain of solid wastes. The amount of carbon emissions created during the transportation of recyclable e-wastes is used as an environmental metric.

The number of affected people is used to estimate the negative effects of MSWM facilities on local communities. According to the research trend, all aspects of sustainability are currently being addressed in the context of MSWM. However, as pointed out by Eskandarpour et al. [22], there is a research need for a broader consideration of social and environmental impact matrices. Aside from the global warming potential, the use of other LCA-based environmental impact indicators needs to be explored. Indicators that have been used by LCA studies to evaluate the environmental performance of MSWM systems are summarized in the review papers by Khandelwal et al. [23] and Yadav and Samadder [24].

As already pointed out, there is a lack of studies about how justice affects the sustainability performances of an MSWM system. The development of MSWM infrastructure that positively contributes to environmental and social justice must be based on a careful evaluation of the current stage of urban development and ongoing injustice issues [2527]. There is a difference between social and environmental justice problems in developed and developing countries. Developed countries generally experience inequalities for side effects of urban growth such as air pollution, waste water, and traffic congestion. In developing countries and low-density cities, the problems are more related to spatial inequalities of economic development activities, sanitation services, and allocation of public resources. As shown in the case of the Perth Metropolitan area, people living in the outer suburbs have the least accessibility provided by car and public transport to job, education, shopping, and healthcare opportunities [28]. The case of plastic bag waste in Nairobi, Kenya, is a typical example of environmental justice issues associated with the disproportionate share of sanitary services and environmental protection policy [29]. The case study describes how political influences on local businesses result in unsustainable patterns of production and consumption of plastic bags, and, thereby, there is a vast accumulation of solid and plastic wastes in communities with low socioeconomic status.

In addition to pollution problems, land-use issues are also critical issues in MSWM planning. Agyeman and Evans [30] explore urban development initiatives that demonstrate inherent links between environmental justice and sustainability issues. They point out that solid waste and landuse planning are common concerns for both environmental justice and sustainability. A land-use policy should focus on preventing disproportionate land-use impacts within or among communities. Without adequate land-use and environmental justice policies, solid waste facilities are likely to be located in poor and minority communities as discovered by Norton et al. [31] when focusing on North Carolina waste infrastructure.

This study addresses the three fundamental sustainability dimensions: environmental, social, and economic, in the context of MSWM in rapidly urbanized regions. To bridge the research gap and contribute to the field of sustainable MSWM, this develops a social impact metric based on environmental justice and incorporate it into a sustainable SCND model for MSWM system. Specifically, the issue of environmental justice related to land-use stress caused by MSWM facility establishment is considered. The inclusion of a land-use equality objective is used to obtain a balanced network design where land-use stress is fairly distributed across an area. Furthermore, the damage of MSWM to human health is also introduced as a measure for the environmental impact of an MSWM system. We use the disability-adjusted life years (DALYs) metric, according to the life-cycle impact assessment (LCIA) method. Despite being used by WHO as a measure of the global burden of disease for many years, there have been very limited applications of DALYs in both the supply chain and the waste management literature. Lastly, facility and transportation costs are taken into account to evaluate the economic aspects of sustainability.

\section{Methodology}

3.1. Public Health Impact Assessment. In this study, the public health impact is defined as the overall mortality and disease burden of nearby residents caused by MSWM facilities and waste transport activities. The public health impact is estimated in units of disability-adjusted life years (DALYs), which is one of the well-established endpoint LCIA metrics. DALYs represent the number of years of life lost due to premature mortality and healthy years of life lost due to disability [32]. We translate the impact of waste management operations and waste transportation into DALYs per person 


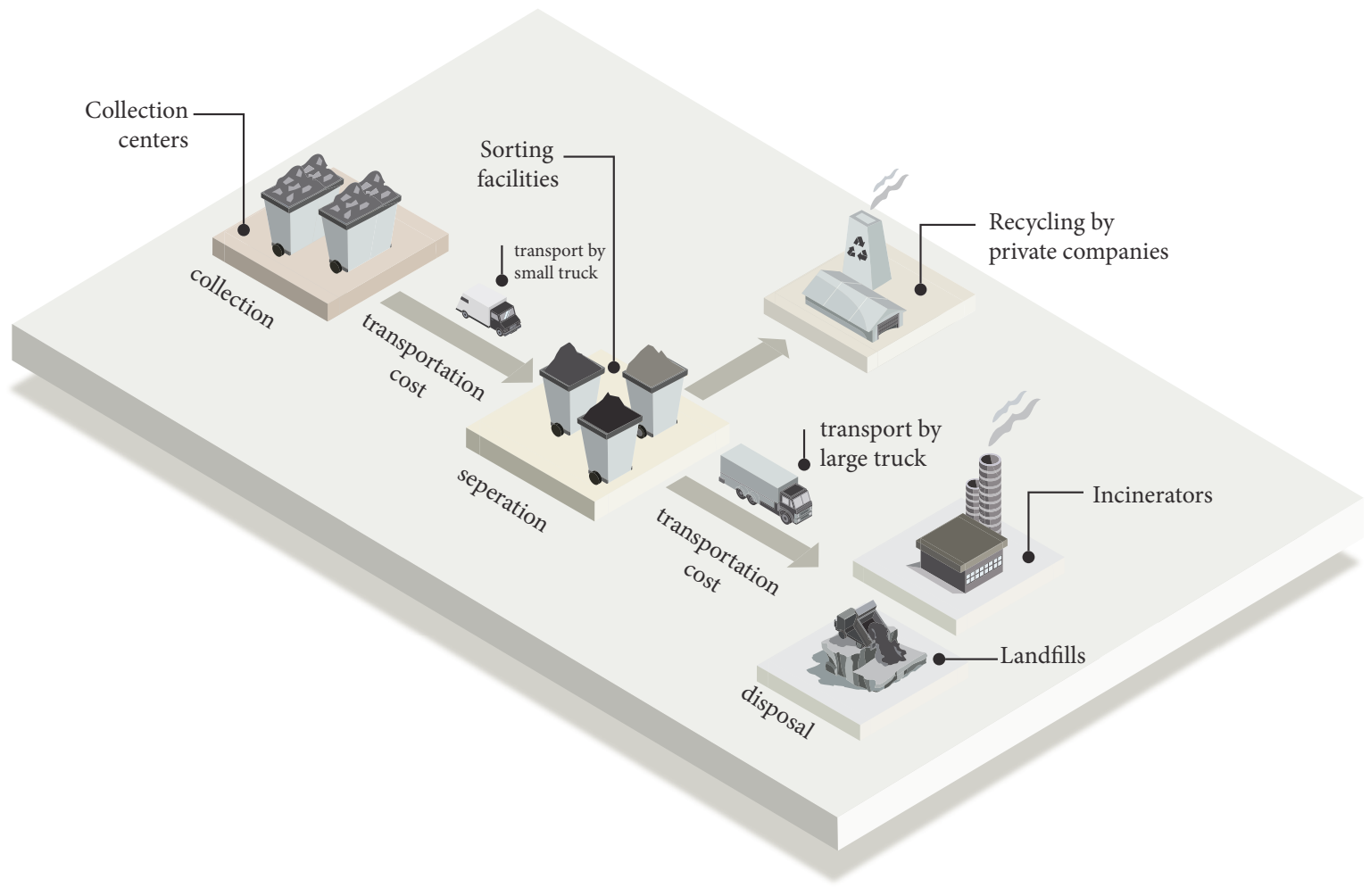

FiguRE 2: Waste management supply chain.

using the ReCiPe 2008 Endpoint LCIA method [33]. Then, the total DALYs are obtained by multiplying the individual impact of exposure by the total number of people living within the affected area.

\subsection{Land-Use Impact Assessment. Processes in MSWM facil-} ities including construction, operation, and closure normally take place over long timescales. Under traditional centralized waste systems, the life expectancy of MSWM facilities is longer, due to the need for larger-sized facilities to cope with increased waste generation in cities. Communities surrounding waste facilities have to deal with the long-term negative external effects of municipal solid waste. Therefore, the issue of disproportionate environmental burden among population in certain areas is a pressing concern, especially for rapidly urbanized cities. From a strategic point of view, it is important that each administrative area in a city is not overly burdened by land-use impact or other important environmental stressors caused by MSWM facilities. The principle of environmental justice must be adopted at the early phase of MSWM planning.

In this study, the spatial planning of MSWM infrastructure uses a land-use equality strategy to mitigate the impact on local land-use in areas with substantial land-use stress. The proposed planning approach involves a two-step process. The first step is to evaluate the current land availability in each geographical or administrative area within a city. This step generally requires knowledge of land-use policies and the use of GIS tools to screen out portions of land which are not suitable for development. The second step is to calculate the land-use stress of each administrative area, which is the ratio of land-use impact caused by MSWM facilities to the available land. In our study, the level of land-use impact is calculated based on the total amount of direct and indirect land-use. The direct land-use is the actual land area used for facility establishment. The indirect land-use is estimated by land occupation LCIA methodology, which assesses the impact on land quality over a given period. The ReCiPe Midpoint (H) V1.07/Europe ReCiPe H method is used in our study to account for the land occupation impact based on the type and capacity of facilities. Previous attempts to integrate direct and indirect land-use impacts have been made in LCA studies to account for the relevant land-use impacts $[34,35]$.

3.3. Optimization Model for Sustainable MSWM. In this section, we introduce a mathematical formulation for the sustainable MSWM problem. The multiobjective mixedinteger model is a customization of the popular facility location model. We consider a 3-echelon supply chain, where solid wastes are gathered in collection centers, then moved to sorting facilities, and finally sent to either incinerators or landfills. Figure 2 shows an example of this supply chain.

We assume that decisions can be made on both locations and sizes of tier 2 and tier 3 of the supply chain (i.e., sorting 
facilities and landfills/incinerators). This directly affects the capacity of each facility, its land-use, and its impact on public health. The objective is to identify locations, sizes, and routes to minimize costs, land-use, and public health impact. Superscripts $S, I$, and $L$ are used throughout the mathematical formulation to refer to sorting, incinerator, and landfill facilities, respectively.

The model's notation is given below:

\section{Sets and Indices}

(i) $I$ is the set of collection centers, indexed by $i$;

(ii) $J$ is the set of sorting facility locations, indexed by $j$;

(iii) $K$ is the set of incinerator locations, indexed by $k$;

(iv) $K^{\prime}$ is the set of landfill locations, indexed by $k^{\prime}$;

(v) $L(j), L(k), L\left(k^{\prime}\right)$ are the set of available sizes at locations $j, k$, and $k^{\prime}$, indexed by $l$.

\section{Parameters}

(i) $t_{i j}, t_{j k}, t_{j k^{\prime}}$ are the transportation costs on links $(i, j),(j, k)$, and $\left(j, k^{\prime}\right)$, respectively;

(ii) $c_{j l}^{S}, c_{k l}^{I}, c_{k^{\prime} l}^{L}$ are the fixed costs to open facilities of size $l$;

(iii) $C_{j l}^{S}, C_{k l}^{I}, C_{k^{\prime} l}^{L}$ are the storage capacities of facilities of size $l$;

(iv) $\bar{C}_{i j}, \bar{C}_{j k}, \bar{C}_{j k^{\prime}}$ define the maximum amount of waste that a single trip can carry over links $(i, j),(j, k)$, and $\left(j, k^{\prime}\right)$, respectively;

(v) $o_{j}^{S}, o_{k}^{I}, o_{j k^{\prime}}^{L}$ are unit operations costs to manage the flow of solid waste, for each facility;

(vi) $s_{j l}^{S}, s_{k l}^{I}, s_{k^{\prime} l}^{L}$ are land-use stress ratios for facilities of size $l$;

(vii) $D_{i}$ is the amount of solid waste available at collection center $i$;

(viii) $p_{i j}, p_{j k}, p_{j k^{\prime}}$ are the number of people living nearby links $(i, j),(j, k)$, and $\left(j, k^{\prime}\right)$, respectively;

(ix) $p_{j l}^{S}, p_{k l}^{I}, p_{k^{\prime} l}^{L}$ are the number of people living near a facility of size $l$;

(x) $d_{i j}, d_{j k}, d_{j k^{\prime}}$ are the DALYs per person, due to transportation activities on links $(i, j),(j, k)$, and $\left(j, k^{\prime}\right)$, respectively;

(xi) $d_{j l}^{S}, d_{k l}^{I}, d_{k^{\prime} l}^{L}$ are the DALYs per person, due to size $l$ facility operations.

\section{Decision Variables}

(i) $y_{j l}^{S}, y_{k l}^{I}, y_{k^{\prime} l}^{L}$ are binary location variables, equal to 1 when sorting facilities, incinerators, and landfills of size $l$ are open at their respective locations $j, k$, and $k^{\prime}$;

(ii) $x_{i j}, x_{j k}, x_{j k^{\prime}}$ are the number of trips on links $(i, j),(j, k)$, and $\left(j, k^{\prime}\right)$, respectively; (iii) $f_{i j}, f_{j k}, f_{j k^{\prime}}$ denote the amount of solid waste transported on links $(i, j),(j, k)$, and $\left(j, k^{\prime}\right)$, respectively.

The cost function $F_{c}$ is computed as follows.

$$
\begin{aligned}
F_{c}= & \sum_{j \in J} \sum_{l \in L(j)} c_{j l}^{S} y_{j l}^{S}+\sum_{k \in K} \sum_{l \in L(k)} c_{k l}^{I} y_{k l}^{I}+\sum_{k^{\prime} \in K^{\prime}} \sum_{l \in L\left(k^{\prime}\right)} c_{k^{\prime} l}^{L} y_{k^{\prime} l}^{L} \\
& +\sum_{i \in I} \sum_{j \in J}\left(t_{i j}+o_{j}^{S}\right) x_{i j}+\sum_{j \in J} \sum_{k \in K}\left(t_{j k}+o_{k}^{I}\right) x_{j k} \\
& +\sum_{j \in J} \sum_{k^{\prime} \in K^{\prime}}\left(t_{j k^{\prime}}+o_{k^{\prime}}^{L}\right) x_{j k^{\prime}}
\end{aligned}
$$

The overall cost is the sum of the fixed costs to open sorting facilities, incinerators, and landfills plus the operational costs of transporting and managing the solid waste flow across the network.

A second function $F_{u}$ is introduced to measure the average land-use stress. The function is formally defined as follows.

$$
F_{u}=\sum_{j \in J} \sum_{l \in L(j)} s_{j l}^{S} y_{j l}^{S}+\sum_{k \in K} \sum_{l \in L(k)} s_{k l}^{I} y_{k l}^{I}+\sum_{k^{\prime} \in K^{\prime}} \sum_{l \in L\left(k^{\prime}\right)} s_{k^{\prime} l}^{L} y_{k^{\prime} l}^{L}
$$

The function is the sum of all the land-use ratio across all candidate locations. Parameters $s_{j l}, s_{k l}, s_{k^{\prime} l}$ represent the ratios for land used and land available. This ratio can be computed by looking at the entire network or by narrowing down the focus to smaller districts, to compute the impact of land-use at a local level.

Finally, a third function $F_{h}$ is used to evaluate the impact of transportation and facilities on the population's health. The function is defined as follows.

$$
\begin{aligned}
F_{h}= & \sum_{j \in J} \sum_{l \in L(j)} p_{j l}^{S} d_{j l}^{S} y_{j l}^{S}+\sum_{k \in K} \sum_{l \in L(k)} p_{k l}^{I} d_{k l}^{I} y_{k l}^{I} \\
& +\sum_{k^{\prime} \in K^{\prime}} \sum_{l \in L\left(k^{\prime}\right)} p_{k^{\prime} l}^{L} d_{k^{\prime} l}^{L} y_{k^{\prime} l}^{L} \sum_{i \in I} \sum_{j \in J} p_{i j} d_{i j} x_{i j} \\
& +\sum_{j \in J} \sum_{k \in K} p_{j k} d_{j k} x_{j k}+\sum_{j \in J} \sum_{k^{\prime} \in K^{\prime}} p_{j k^{\prime}} d_{j k^{\prime}} x_{j k^{\prime}}
\end{aligned}
$$

The Sustainable Waste Management Network (SWMN) design model can be formulated as a multiobjective mixedinteger program.

$$
\begin{aligned}
\text { [SWMN]: } \min & \left\{F_{c}, F_{u}, F_{h}\right\} \\
\text { s.t. } & \sum_{j \in J} f_{i j}=D_{i} \quad \forall i \in I \\
& \sum_{i \in I} f_{i j}=\sum_{k \in K} f_{j k} \quad \forall j \in J
\end{aligned}
$$




$$
\begin{aligned}
& \sum_{i \in I} f_{i j} \leq \sum_{l \in L(j)} C_{j l} y_{j l}^{S} \quad \forall j \in J \\
& \sum_{j \in J} f_{j k} \leq \sum_{l \in L(k)} C_{k l} y_{k l}^{I} \quad \forall k \in K \\
& \sum_{j \in J} f_{j k^{\prime}} \leq \sum_{l \in L\left(k^{\prime}\right)} C_{k^{\prime} l} y_{k^{\prime} l}^{L} \quad \forall k^{\prime} \in K^{\prime} \\
& f_{i j} \leq \bar{C}_{j l} x_{i j} \quad \forall i \in I, \quad j \in J \\
& f_{j k} \leq \bar{C}_{k l} x_{j k} \quad \forall j \in J, k \in K \\
& f_{j k^{\prime}} \leq \bar{C}_{k^{\prime} l} x_{j k^{\prime}} \quad \forall j \in J, k \in K \\
& \sum_{l \in L(j)} y_{j l}^{S} \leq 1 \quad \forall j \in J \\
& \sum_{l \in L(k)} y_{k l}^{I} \leq 1 \quad \forall k \in K \\
& \sum_{l \in L\left(k^{\prime}\right)} y_{k^{\prime} l}^{L} \leq 1 \quad \forall k^{\prime} \in K^{\prime} \\
& f_{i j}, f_{j k}, f_{j k^{\prime}} \geq 0 \quad \forall i, j, k, k^{\prime} \\
& y_{j l}^{S}, y_{k l}^{I}, y_{k^{\prime} l}^{L} \in\{0,1\} \quad \forall j, k, k^{\prime}, l \\
& x_{i j}, x_{j k}, x_{j k^{\prime}} \in \mathbb{Z}^{+} \quad \forall i, j, k, k^{\prime} \\
&
\end{aligned}
$$

The objective (4) is to minimize the costs, land-use ratios, and impact of transportation. Constraints (5) state that the outflow of waste from any given collection center $i$ must be equal to $D_{i}$. Equations (6) are flow balance constraints, enforcing that the inflow at a sorting facility $j$ is entirely forwarded to incinerators $k$ and landfills $k^{\prime}$. Constraints (7)(9) are the size-dependent capacity constraints at any facility of the network. Constraints (10)-(12) are the transportation capacity limitations. Inequalities (13)-(15) enforce that only one size can be selected if a facility is open at a given location. Constraints (16)-(18) define the decision variables' domains.

3.4. Solution Algorithms. The computational results, displayed in Section 4, are obtained from various optimization models solved under single-objective functions and multiobjective functions. We refer to these models using the notation SWMN(), where we define inside the brackets the objectives being optimized together. For example, $\operatorname{SWMN}\left(F_{c}, F_{h}\right)$ is the multiobjective problem optimizing both costs and health impact whereas $\operatorname{SWMN}\left(F_{u}\right)$ is the single-objective model minimizing only the land-use impact. Single-objective models can be solved with numerical methods such as branch and bound method. As for multiobjective models, a min-max approach is implemented to identify solutions that minimize the deviations from the ideal results. Formally, let $F_{c}^{*}, F_{u}^{*}$, and $F_{h}^{*}$ be the optimal value obtained by solving the respective single-objective problems. Furthermore, let $F_{c}^{\max }, F_{u}^{\max }$, and $F_{h}^{\max }$ upper bounds be set equal to the worst value obtained by each function across the single-objective problems. We can now define the deviation levels between each objective and its ideal target by normalizing the functions as follows.

$$
\begin{gathered}
\sigma_{c}=\frac{F_{c}-F_{c}^{*}}{F_{c}^{\text {max }}-F_{c}^{*}} \\
\sigma_{u}=\frac{F_{u}-F_{u}^{*}}{F_{u}^{\text {max }}-F_{u}^{*}} \\
\sigma_{h}=\frac{F_{h}-F_{h}^{*}}{F_{h}^{\text {max }}-F_{h}^{*}}
\end{gathered}
$$

By adding a new continuous decision variable $z$, we can formulate a min-max goal attainment on the deviations of three objectives as follows.

$$
\begin{aligned}
\left.\operatorname{SWMN}\left(F_{c}, F_{u}, F_{h}\right)\right]: \min & z \\
\text { s.t. } & \sigma_{c} \leq z \\
& \sigma_{u} \leq z \\
& \sigma_{h} \leq z \\
& (5)-(18)
\end{aligned}
$$

The objective of min-max SWMN is to minimize the largest deviation from optimal targets across the three functions considered. The model can be easily modified to target only two objectives.

\section{Case Study}

In this section, we apply the proposed SWMN model to a case study in Pathum Thani province in Thailand. The waste management system in Thailand is of interest as very little planning has been used in the past to locate waste facilities. Nowadays, among a total of 2,490 municipal solid waste sites, only 499 (20\%) adopt safety standards, such as sanitary/engineer landfill, controlled dumping, and incineration with air pollution-controlled system [36]. The rest of the sites implement unhealthy practices such as open dumping and incineration without air pollution-controlled system. As a consequence, the uncontrolled release of leachates and gases from these dumps is frequent. This is taking a toll on both environment and society. For example, in 2010 a fire broke out at the Phraeksa dump site causing hundreds of residents to flee the area. This incident prompted local governments across Thailand to reexamine their regulatory approaches in health and environmental safety.

Pathum Thani is located in the central region of Thailand, within the Bangkok metropolitan area (Figure 3). It covers a total area of $1,525.9 \mathrm{~km}^{2}$, organized into 7 districts, 60 subdistricts, and 529 villages. Its population has steadily increased in the past decade to about 1.2 million. As a result, the amount of waste generated increased to 0.612 million tonnes/year [36]. As the province is quite vast, we narrow the focus to Muang Pathum Thani, Sam Khok, and Lat Lum Kaeo districts for our case study (Figure 4). Currently, solid wastes from communities are gathered at collection centers across 
TABLE 1: Safety distance from waste facilities.

\begin{tabular}{lccc}
\hline Criteria & Sorting facility $(\mathrm{km})$ & Incinerator $(\mathrm{km})$ & Landfill $(\mathrm{km})$ \\
\hline Residential area & 1 & 2 & 1 \\
Archaeological heritage site & 1 & 1 & 1 \\
River & 1 & 1 & 1 \\
Pond & - & 0.3 & 0.3 \\
Main road & - & 0.3 & 0.3 \\
\hline
\end{tabular}

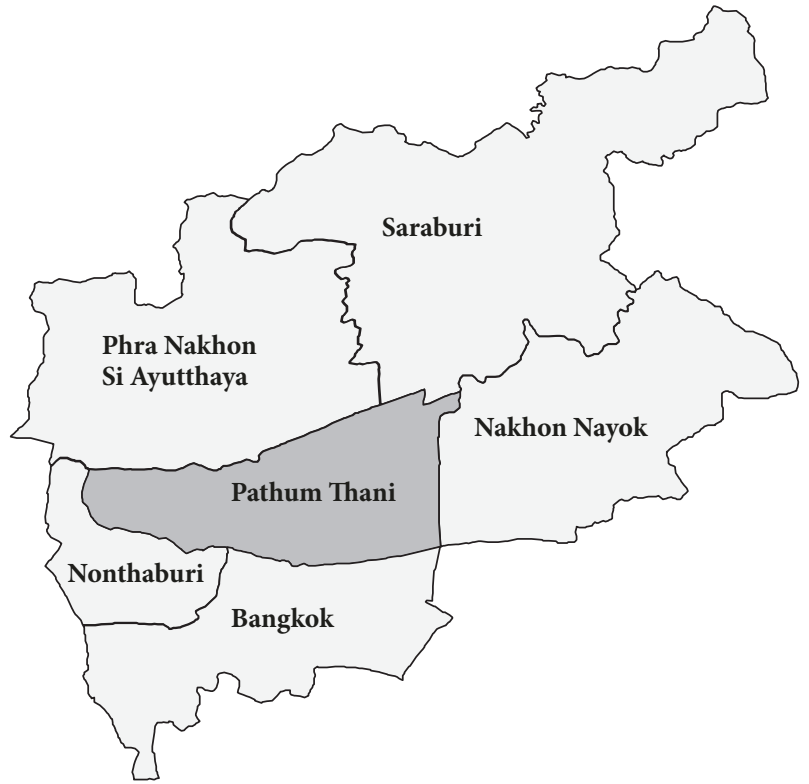

FIgURE 3: Central Thailand.

subdistricts. Wastes at collection centers are transported to sorting facilities and subsequently sent to either incinerators or landfills. Recycling is purposely not included in this study as it is currently done by private companies. The validation of the proposed model is done by determining the location and size of sorting and disposal facilities.

\subsection{Parameters}

Land Availability Assessment and Candidate Locations. In order to quantify the land available, an initial screening is necessary to exclude from the analysis places such as rivers, ponds, main roads, archaeological heritage sites, and residential areas. We further include a buffering area to guarantee safe distances between waste sites. As shown in Table 1, the size of these buffers is set according to the regulation and guideline of MSWM developed by the Pollution Control Department (PCD).

A number of polygons are identified by combining available land with subdistrict boundaries. Based on their sizes, these polygons are further divided and their centroid is selected as a facility location. Available land for landfill siting is shown in Figure 4. Since candidate locations of the three types of facilities overlap, we further constrain the mathematical model to avoid colocations.
To ensure environmental justice across the three districts, we perform the land-use assessment at the subdistrict level. For any location within a subdistrict, we compute parameters $s_{j l}^{S}, s_{k l}^{I}$ and $s_{k^{\prime} l}^{L}$ as the following ratio.

$$
\frac{\text { Direct }+ \text { Indirect land use, with facility of size } l}{\text { Total land available in the sub-district }}
$$

For each facility, 3 capacity levels are considered: small, medium, and large. Their direct and indirect land-use are shown in Table 2 . The values are estimated by land occupation LCIA methodology as previously described in our land-use impact assessment.

Traveling Distances. All wastes are transported from the collection centers to the sorting facilities using 16-tonne (light) trucks. From the sorting facilities to both the incinerator and landfill sites, 32-tonne (heavy) trucks are used. Traveling distances are estimated using ArcGIS and a digital map of Pathum Thani. Specifically, having defined the candidate locations, we use a network analysis tool to determine the shortest routes.

Public Health Impact Assessment. To measure the public health impact, this study computes the DALYs for people affected by the MSWM system. The first step is to estimate the number of people living near the supply chain. No data is currently available showing the population distribution at the household level. ArcGIS is used to count the total number of residential buildings surrounding the waste transportation routes and MSWM facilities.

To estimate the damage to public health caused by an MSWM system, this study adopts the emission-to-exposure model used by Gouge et al. [37] and Greco et al. [38]. They use several buffer distances to estimate the health impact caused by transport pollution. In our study, we set the buffer distance for transportation routes to $100 \mathrm{~m}$. For MSWM facilities, the affected areas are assumed to increase with the waste disposal dimension. Moreover, due to a long history of unsanitary practices in Thailand, landfills are assumed to have a larger impact than other MSWM facilities (Table 3).

The estimation of the number of affected people is made based on the information of the total population living in the area and the number of residential buildings. The proposed estimation approach is expected to give a more accurate estimate of affected people than the previous approach [39]. Varying impact distances, corresponding to different types and sizes of facilities, are used instead of one single impact distance. The second step is to multiply the number of affected 


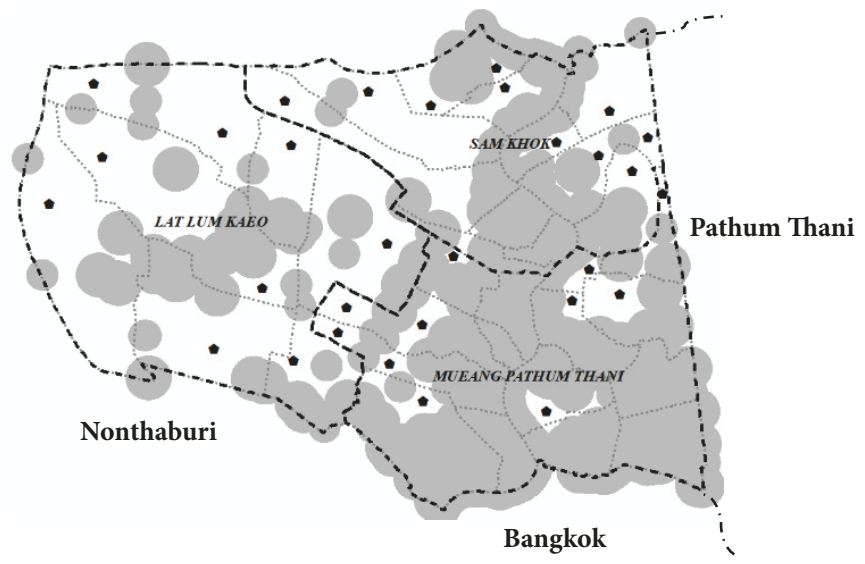

Candidate landfill siting locations

Unsuitable area for landfill siting

FIGURE 4: Landfill locations.

TABLE 2: Direct and indirect land-use impacts.

\begin{tabular}{|c|c|c|c|c|c|c|}
\hline \multirow[b]{2}{*}{ Waste facility } & \multicolumn{3}{|c|}{ Direct land-use $\left(m^{2}\right)$} & \multicolumn{3}{|c|}{ Indirect land-use $\left(\mathrm{m}^{2}\right)$} \\
\hline & Small size & Medium size & Large size & Small size & Medium size & Large size \\
\hline Sorting facility & 4,800 & 8,000 & 16,000 & 6,191 & 10,780 & 21,559 \\
\hline Incinerator & 8,000 & 16,000 & 24,000 & 11,971 & 23,941 & 35,911 \\
\hline Landfill & 80,000 & 160,000 & 192,000 & 127,770 & 255,525 & 335,295 \\
\hline
\end{tabular}

TABLE 3: Facilities impact on public health.

\begin{tabular}{|c|c|c|c|c|}
\hline Facilities & Sized & Capacity (tonne/day) & Affected areas $(\mathrm{km})$ & $\overline{\text { DALYs }}$ \\
\hline \multirow{3}{*}{ Sorting Facility } & Small & 50 & 0.3 & 0.07 \\
\hline & Medium & 100 & 0.6 & 0.14 \\
\hline & Large & 300 & 1.8 & 0.28 \\
\hline \multirow{3}{*}{ Incinerator } & Small & 50 & 0.5 & 5.95 \\
\hline & Medium & 100 & 1 & 11.9 \\
\hline & Large & 150 & 1.5 & 17.85 \\
\hline \multirow{3}{*}{ Landfill } & Small & 50 & 1 & 3.89 \\
\hline & Medium & 100 & 2 & 7.78 \\
\hline & Large & 150 & 3 & 11.66 \\
\hline
\end{tabular}

people near the transportation routes and MSWM facilities by the DALYs coefficients, which are summarized in Tables 3 and 4 . The number of DALYs is estimated based on a 30-year operational period, using the ReCiPe 2008 Endpoint LCIA method [33]. Only local-scale environmental impacts are taken into account, including human toxicity, photochemical oxidant formation, PM formation, and ionizing radiation. The damage due to climate change and ozone depletion is neglected. Finally, the capacity of waste sites and trucks is selected from those available in SimaPro 7.3 (LCA software) which covers a wide range of typical facilities and operations. The entire dataset can be found in Kachapanya [40].
4.2. Results and Discussion. This section presents the results from the computational analysis which is carried out on a Windows 10 machine using an Intel i7-6700HQ processor with 8 GB of RAM. CPLEX 12.6 optimization studio is used to solve the mathematical models. The analysis is organized in two subsections: single-objective and multiobjective optimizations.

The results are interpreted in terms of satisfaction levels of each objective. A satisfaction level of $100 \%$, indicates that the objective is equal to its optimal level. Conversely, smaller satisfaction levels indicate that there is a gap between the objective and its best achievable target. Formally, these levels 
TABLE 4: Transportation impact on public health.

\begin{tabular}{lcccc}
\hline Fleet types & Capacity (ton) & Affected areas $(\mathrm{km})$ & DALYs Empty load $(\mathrm{per} \mathrm{km})$ & DALYs full load $($ per tkm) \\
\hline Light truck & 16 & 0.1 & $5.82 \cdot 10^{-7}$ & $5.62 \cdot 10^{-8}$ \\
Heavy truck & 32 & 0.1 & $1.16 \cdot 10^{-6}$ & $1.12 \cdot 10^{-7}$ \\
\hline
\end{tabular}

TABLE 5: Results of single-objective optimization.

\begin{tabular}{|c|c|c|c|c|}
\hline & & Minimizing Cost & $\begin{array}{l}\text { Minimizing Avg. } \\
\text { Land-Use Stress }\end{array}$ & $\begin{array}{c}\text { Minimizing Public } \\
\text { Health Impact }\end{array}$ \\
\hline \multirow{6}{*}{ Total Cost (USD) } & $\begin{array}{c}\text { Total transportation } \\
\text { cost }\end{array}$ & $11,973,205$ & $23,519,346$ & $9,658,807$ \\
\hline & Total land cost & $7,753,691$ & $1,854,007$ & $21,035,012$ \\
\hline & $\begin{array}{c}\text { Total construction } \\
\text { cost }\end{array}$ & $17,114,396$ & $19,456,136$ & $27,692,869$ \\
\hline & Total operation cost & $14,103,023$ & $19,823,517$ & $16,354,068$ \\
\hline & Total cost & $50,944,315$ & $64,653,006$ & $74,740,757$ \\
\hline & Satisfaction Level & $100 \%$ & $42 \%$ & $0 \%$ \\
\hline \multirow{2}{*}{ Land-Use Impact } & Avg. Land-use Stress & 0.573 & 0.028 & 0.985 \\
\hline & Satisfaction Level & $43 \%$ & $100 \%$ & $0 \%$ \\
\hline \multirow{4}{*}{$\begin{array}{l}\text { Public Health Impact } \\
\text { (DALY) }\end{array}$} & Transportation & 13,042 & 47,868 & 6,214 \\
\hline & Waste Facilities & 31,639 & 10,072 & 1,010 \\
\hline & $\begin{array}{l}\text { Total Public Health } \\
\text { Impact }\end{array}$ & 44,681 & 57,940 & 7,224 \\
\hline & Satisfaction Level & $26 \%$ & $0 \%$ & $100 \%$ \\
\hline \multicolumn{2}{|c|}{ Average Satisfaction Level } & $56 \%$ & $47 \%$ & $33 \%$ \\
\hline \multicolumn{2}{|c|}{ Computational Time (Sec.) } & 24 & 10 & 13 \\
\hline
\end{tabular}

are obtained from the deviation values introduced in the methodology section (i.e., $1-\sigma_{c}, 1-\sigma_{u}$, and $1-\sigma_{h}$ ).

\subsubsection{Single-Objective Optimization}

Total Cost Optimization ( $\operatorname{SWMN}\left(F_{c}\right)$ ). Figure 5(a) shows the optimal layout of the MSWM system obtained by solving $\operatorname{SWMN}\left(F_{c}\right)$. Results show that when cost is the main driver, the number of facilities is low. Out of 37 candidate locations for sorting facilities, only 6 are selected. Similarly, only 1 incinerator and 3 landfills are selected. While these facilities provide sufficient capacity for all subdistrict, they also generate routes longer than $30 \mathrm{~km}$.

The summary of costs and the average land-use stress associated with the solution are shown in Table 5 under the column named "Minimizing Cost". The construction cost is the largest cost. As a consequence, landfills are chosen over incinerators. The cost-optimum of the MSWM layout is about $50,944,315$ US dollars composed of the transportation (11,973,205 US dollars), land (7,753,691 US dollars), construction (17,114,396 US dollars), and operational costs (14,103,023 US dollars). The average land-use stress and public health impact for this solution are estimated at 0.573 and 44,681 DALYs, respectively. The public health impact is from transportation (13,042 DALY) and waste facilities (31,639 DALYs). This suggests that although $\operatorname{SWMN}\left(F_{c}\right)$ achieves minimum cost, it comes at the expense of public health and land-use. This is mostly due to disposal sites located close to the urban areas where waste is generated, resulting in excessive land-use stress and high public health impact.

Average Land-Use Stress Optimization $\left(\operatorname{SWMN}\left(F_{u}\right)\right)$. Number and location of facilities obtained by solving $\operatorname{SWMN}\left(F_{u}\right)$ are shown in Figure 5(b). Again, the number of open facilities is relatively small. Four sorting facilities and four incinerators are selected. The locations are different, compared to the $\operatorname{SWMN}\left(F_{c}\right)$ case. Sorting facilities and incinerators are located in rural areas, reducing the excessive land-use stress returned by the cost minimization model. No landfill is selected. However, displacing facilities away from urban areas leads to high transportation cost and high public health impact.

The results of average land-use stress are shown in Table 5 under the column named "Minimizing Avg. LandUse Stress". The results show that the total cost is $64,653,006$ US dollars consisting of transportation cost $(24,053,902$ US dollars), land cost (1,896,146 US dollars), construction cost (19,898,341 US dollars), and disposal cost (20,274,072 US dollars). The average land-use stress of the MSWM system drops to 0.028 . The public health impact is 57,940 DALYs (47,868 DALYs from transportation and 10,072 DALYs from waste facilities).

Public Health Impact Optimization $\left(\operatorname{SWMN}\left(F_{h}\right)\right)$. Solving $\operatorname{SWMN}\left(F_{h}\right)$ leads to a layout that is quite different. Most of the facilities are sparsely located across the region (Figure 5(c)). 


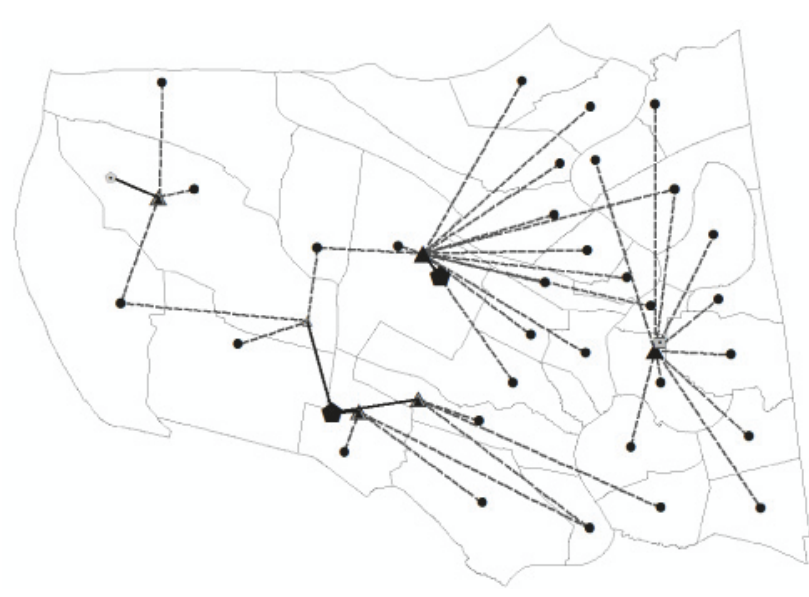

Optimal layout of MSWM system under cost objective

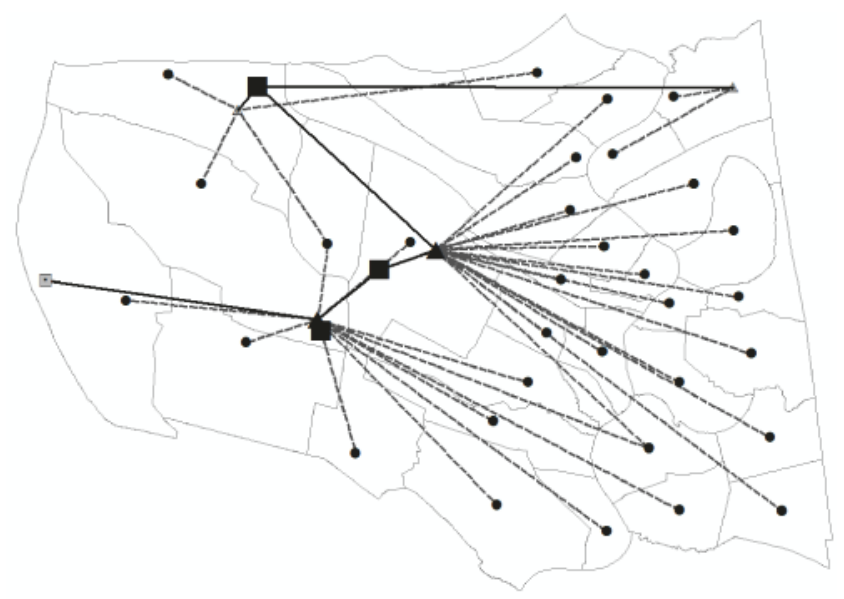

Optimal layout of MSWM system under Avg. land use stress objective

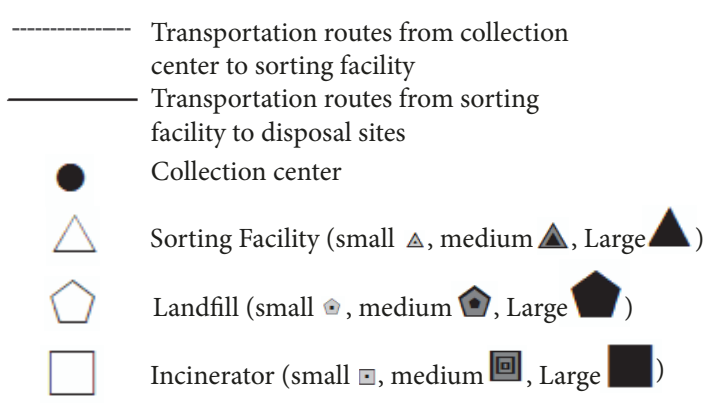

(a)

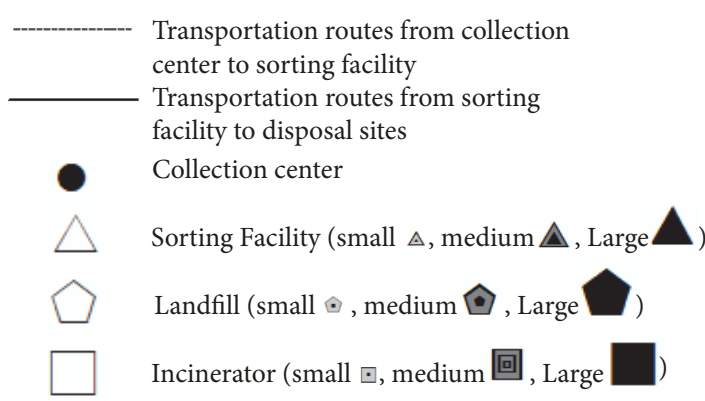

(b)

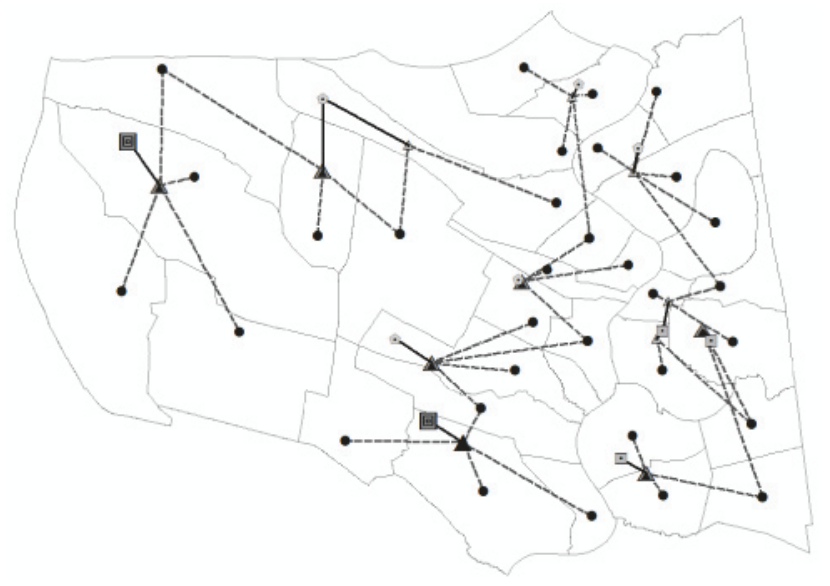

Optimal layout of MSWM system under public health impact objective

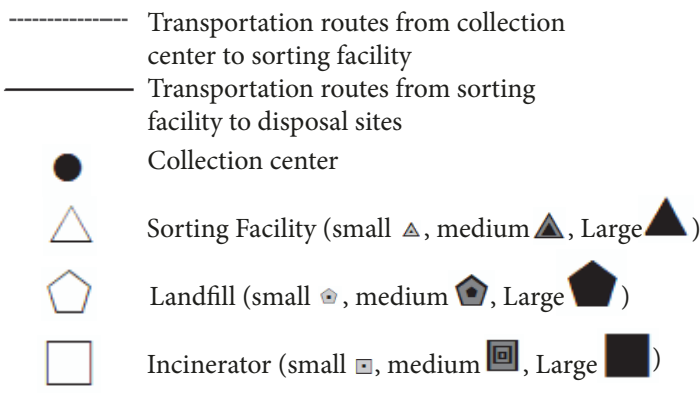

(c)

FIGURE 5: Optimal layouts of MSWM system under single-objective functions. 
TABLE 6: Results of multiobjective optimization.

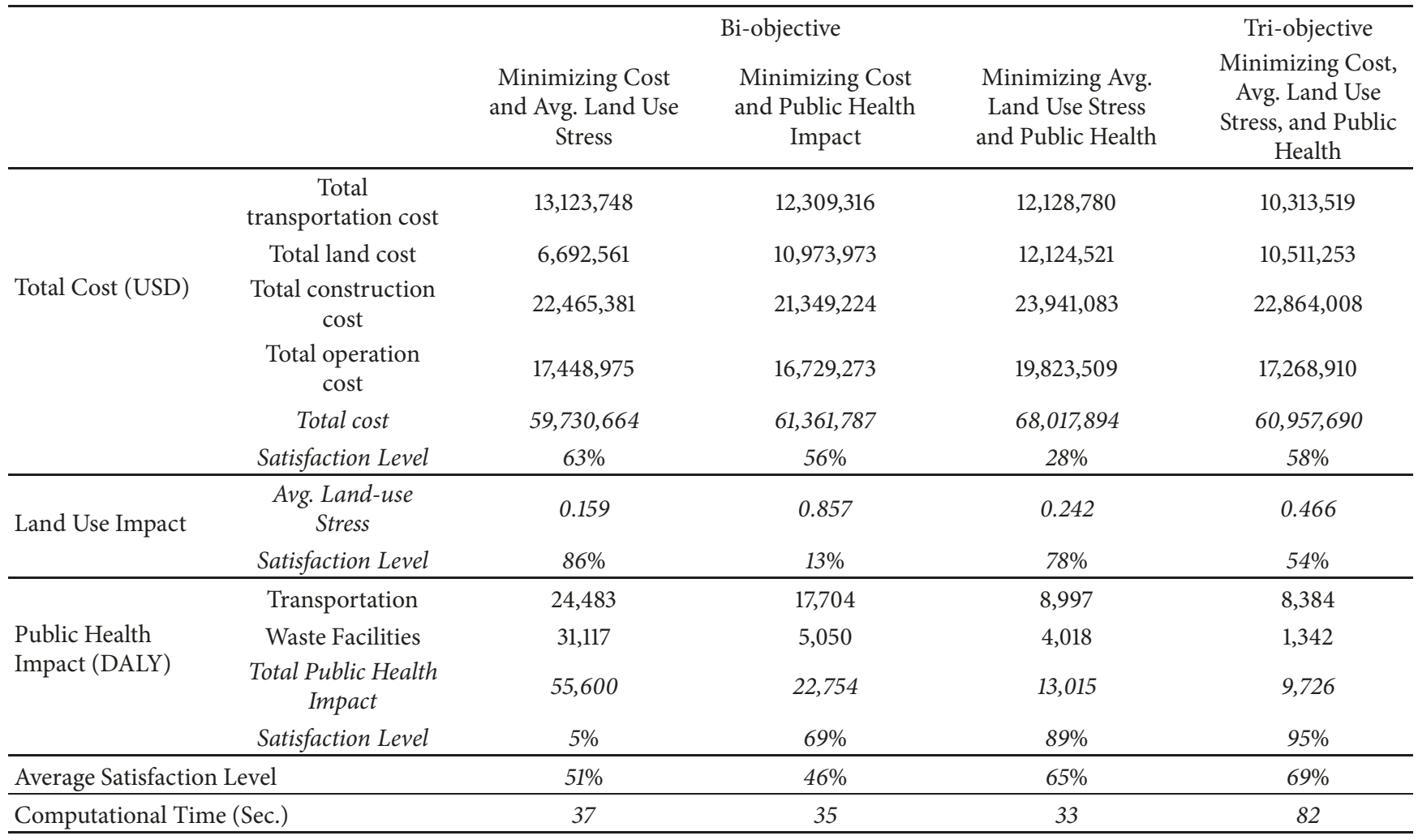

A total of 22 facilities are opened (12 sorting facilities, 5 landfills, and 5 incinerators). Results in Table 5 show that the optimal public health drops to 7,224 DALYs. The average land-use stress and total cost increase to 0.985 and $74,740,757$ US dollars, respectively. As expected, the land cost $(21,035,012$ US dollars) and construction cost (27,692,869 US dollars) are mostly responsible for the cost increment. Clearly, reducing public health is mostly a consequence of reducing the transportation routes. This is also evident by looking at the transportation cost $(9,658,807$ US dollars) which decreases considerably. This is achieved by locating a large number of facilities sparsely across the area. Consequently, the land-use ratio is bound to worsen dramatically.

To sum up, the transportation cost reaches its minimum when $\operatorname{SWMN}\left(F_{h}\right)$ is solved. Its value is $20 \%$ smaller than $\operatorname{SWMN}\left(F_{c}\right)$. However, the land cost from $\operatorname{SWMN}\left(F_{u}\right)$ is lower than $\operatorname{SWMN}\left(F_{c}\right)$ by $76 \%$, and it is lower than $\operatorname{SWMN}\left(F_{h}\right)$ by $91 \%$. For the total construction cost, $\operatorname{SWMN}\left(F_{c}\right)$ is $12 \%$ lower than $\operatorname{SWMN}\left(F_{u}\right)$ because landfills have lower construction cost than incinerators, and it is $38 \%$ lower than $\operatorname{SWMN}\left(F_{h}\right)$ because the number of sorting facilities is smaller. The reason is that incinerators reduce the amount of land required, and the cost of land in urban areas is typically more expensive. The lowest operational cost is from $\operatorname{SWMN}\left(F_{c}\right)$. Moreover, focusing on the land-use stress impact, $\operatorname{SWMN}\left(F_{u}\right)$ results in lower values compared to $\operatorname{SWMN}\left(F_{c}\right)$ and $\operatorname{SWMN}\left(F_{h}\right)(95 \%$ and $97 \%$, respectively). Finally, regarding the public health impact, the $\operatorname{SWMN}\left(F_{h}\right)$ result is lower than $\operatorname{SWMN}\left(F_{c}\right)$ by approximately $84 \%$ and lower than $\operatorname{SWMN}\left(F_{u}\right)$ by approximately $88 \%$.

4.2.2. Multiobjective Optimization. The results and the layouts of MSWM networks are shown in Tables 6 and 7 and Figure 6.

Total Cost and Average Land-Use Stress Optimization $\left(\operatorname{SWMN}\left(F_{c}, F_{u}\right)\right)$. When the problem is solved minimizing costs and land-use, sorting facilities and incinerators are evenly distributed between urban and rural areas. The landfills are located in rural areas due to larger land requirements (Figure 6(a)). This scenario shows the tradeoff between costs and land-use stress. Looking at $\operatorname{SWMN}\left(F_{c}\right)$, land-use stress satisfaction increases from $43 \%$ to $86 \%$ but it deteriorates the total cost satisfaction level by $37 \%$ (Table 6). Due to the higher potential impact of landfill facilities on the overall land-use stress, $\operatorname{SWMN}\left(F_{c}, F_{u}\right)$ reduces the number of facilities to only one large facility (Table 7). However, to satisfy the total demand, three large incinerators are built. Furthermore, the number of sorting facilities increases to 11 (7 small, 1 medium, and 3 large). As expected, this scenario has high satisfaction levels of cost (63\%) and land-use stress $(86 \%)$. Nevertheless, the satisfaction level of the public health objective is extremely low (5\%).

Total Cost and the Public Health $\operatorname{Impact}\left(\operatorname{SWMN}\left(F_{c}, F_{h}\right)\right)$. The results of optimizing costs and public health show that 


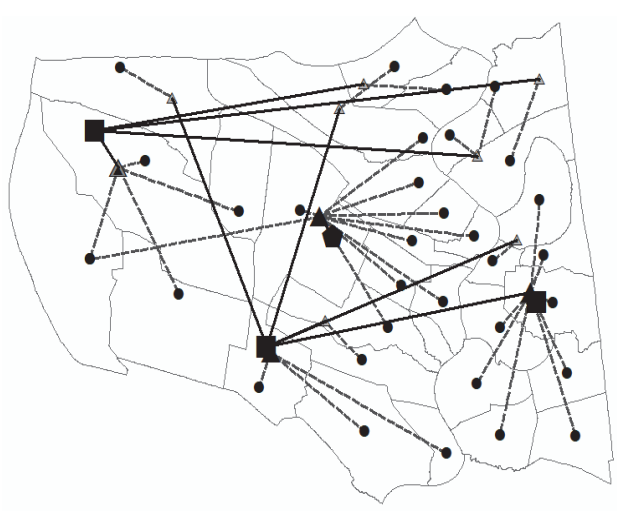

Optimal layout of MSWM system under cost and avg. land use stress objectives

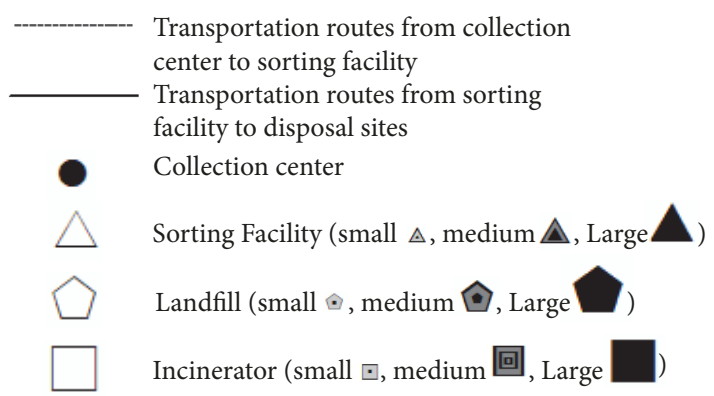

(a)

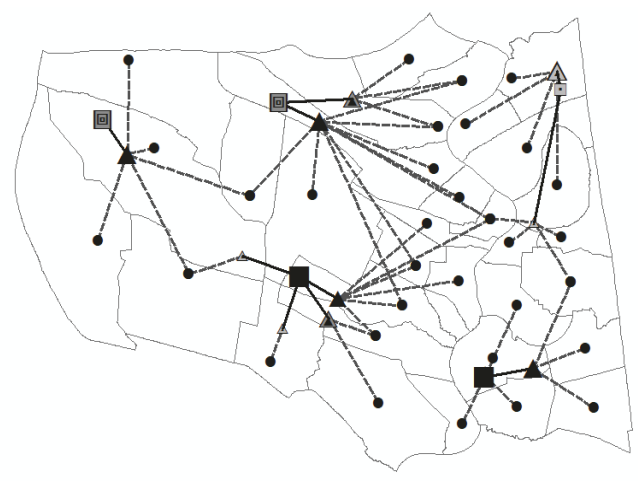

Optimal layout of MSWM system under avg. land use stress,

and public health impact objectives

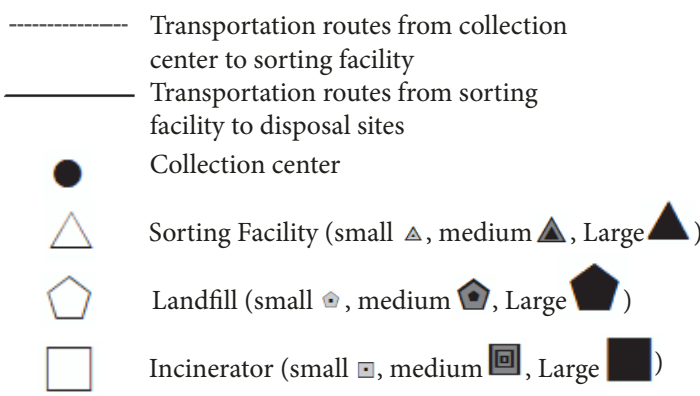

(c)

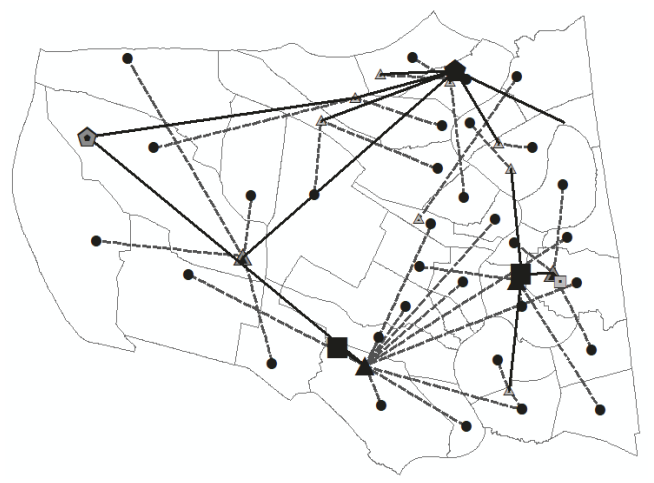

Optimal layout of MSWM system under avg. land use stress, and public health impact objectives

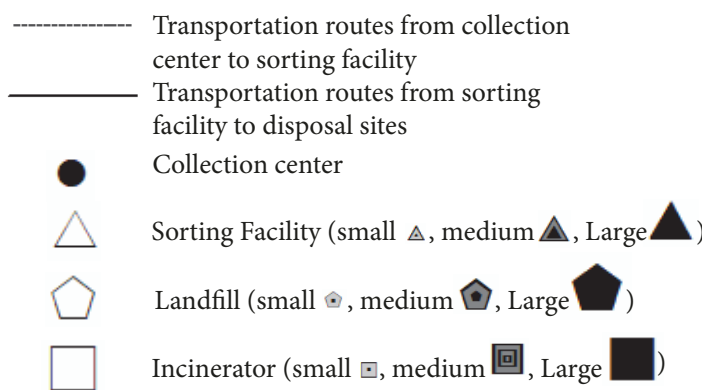

(b)

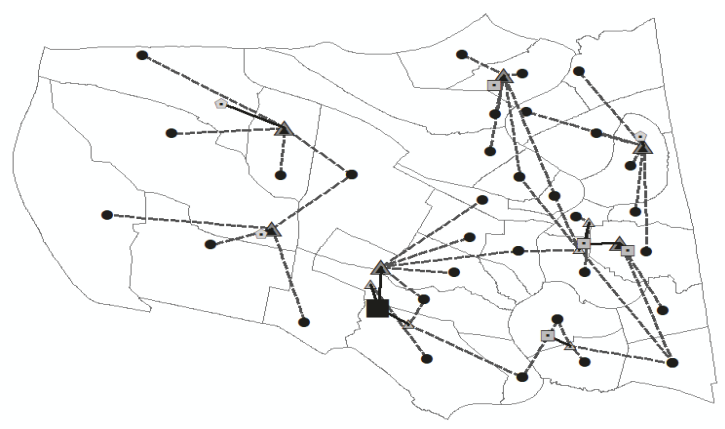

Optimal layout of MSWM system under cost, avg. land use stress, and public health impact objectives

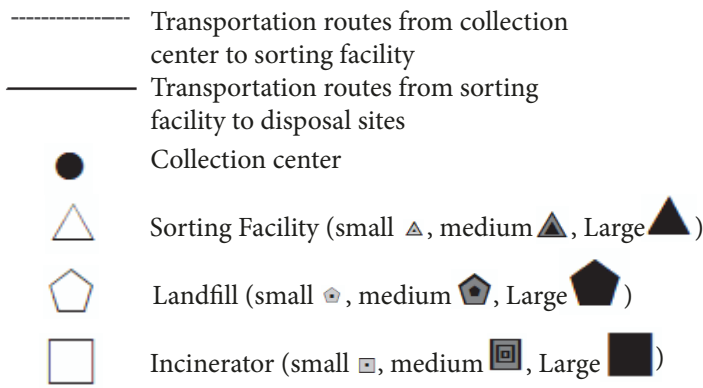

(d)

FIGURE 6: Optimal layouts of MSWM system under multiobjective functions. 
TABLE 7: Number of facilities in the optimization scenarios.

\begin{tabular}{|c|c|c|c|c|c|c|c|c|c|c|}
\hline \multirow{2}{*}{ Scenario } & \multicolumn{3}{|c|}{ Sorting Facility } & \multicolumn{3}{|c|}{ Incinerator } & \multicolumn{3}{|c|}{ Landfill } & \multirow{2}{*}{$\begin{array}{c}\text { Avg. satisfaction } \\
\text { level }\end{array}$} \\
\hline & Small size & Medium size & Large size & Small size & Medium size & Large size & Small size & Medium size & Large size & \\
\hline $\begin{array}{l}\text { Minimizing } \\
\text { cost }\end{array}$ & 1 & 3 & 2 & 0 & 0 & 1 & 1 & 0 & 2 & $56 \%$ \\
\hline $\begin{array}{l}\text { Minimizing } \\
\text { avg. land } \\
\text { use stress }\end{array}$ & 2 & 0 & 2 & 1 & 0 & 3 & 0 & 0 & 0 & $47 \%$ \\
\hline $\begin{array}{l}\text { Minimizing } \\
\text { public } \\
\text { health } \\
\text { impact }\end{array}$ & 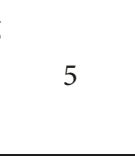 & 6 & 1 & 3 & 2 & 0 & 5 & 0 & 0 & $33 \%$ \\
\hline $\begin{array}{l}\text { Minimizing } \\
\text { cost and } \\
\text { avg. land } \\
\text { use stress }\end{array}$ & 7 & 1 & 3 & 0 & 0 & 3 & 0 & 0 & 1 & $51 \%$ \\
\hline $\begin{array}{l}\text { Minimizing } \\
\text { cost and } \\
\text { public } \\
\text { health } \\
\text { impact }\end{array}$ & 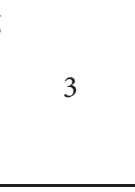 & 3 & 3 & 0 & 0 & 2 & 2 & 0 & 1 & $46 \%$ \\
\hline $\begin{array}{l}\text { Minimizing } \\
\text { avg. land } \\
\text { use stress } \\
\text { and public } \\
\text { health }\end{array}$ & 4 & 2 & 5 & 1 & 2 & 2 & 0 & 0 & 0 & $65 \%$ \\
\hline $\begin{array}{l}\text { Minimizing } \\
\text { cost, avg. } \\
\text { land use } \\
\text { stress, and } \\
\text { public } \\
\text { health }\end{array}$ & 6 & 6 & 0 & 4 & 0 & 1 & 3 & 0 & 0 & $69 \%$ \\
\hline
\end{tabular}

all facilities are sparsely distributed in urban and rural areas (Figure 6(b)). This is because the two objectives share the common goal of reducing the transportation routes so that both health and costs are reduced. From Table 7, the sorting facilities are now three for each size. Two large incinerators are built and three landfills locations are selected ( 2 small 1 large). The average satisfaction is $46 \%$. The satisfaction level of cost is $56 \%$ while the satisfaction level of public health is $69 \%$ (Table 6). This result suggests a clear conflict between these two objectives, despite the common goal of reducing transportation routes.

Average Land-Use Stress and Public Health Impact $\left(\operatorname{SWMN}\left(F_{u}, F_{h}\right)\right)$. Optimizing land-use and health impact disregarding costs results in selecting only incinerators (1 small, 2 medium, and 2 large) due to their lower land-use as opposed to landfills (Figure 6(c)). The number of sorting facilities increases to 11, 5 of which are large, 2 medium, and 4 small. The average satisfaction level is $65 \%$ as land-use stress (78\%) and public health impact (89\%) simultaneously reach high levels (Table 6). However, the satisfaction level of the total cost is reduced dramatically to $28 \%$, suggesting that this solution is not practical.
Total Cost, Average Land-Use Stress and Public Health Impact $\left(\operatorname{SWMN}\left(F_{c}, F_{u}, F_{h}\right)\right)$. Previous results have shown that both single- and biobjective models fail to reach a good compromise. Therefore, the problem is solved minimizing the three objectives at the same time. This leads to an MSWM system layout that is well balanced across the region (Figure 6(d)) as this model mainly chooses small and medium-sized facilities (Table 7). Normally, it is difficult to obtain solutions with high satisfaction levels across all conflicting objectives. However, this scenario gives the highest average satisfaction level (69\%) and offers an effective compromise between the three objectives as each satisfaction level is above $50 \%$.

\section{Concluding Remarks}

In this paper, we propose a novel network design optimization model for MSWM which accounts for sustainability in a comprehensive way. Specifically, we incorporate environmental and social impact indicators with the economic objective. A formal methodology is introduced to model public health and land-use impacts. The first is measured in terms of DALYs imposed by the waste operations on 
the population living close to the supply chain. To enforce a fair use across a city's subdistricts, the land-use metric is computed as the ratio between used and available land. The multiobjective formulation is translated into a singleobjective model aiming to minimize the maximum gap of each objective from its optimal target.

A case study in Pathum Thani (Thailand) is developed to validate the model while also providing results that can be of public interest, to increase awareness and engage with local stakeholders. The single-objective analysis highlights the fact that focusing only on cost generates a supply chain which imposes a serious burden on society. In fact, the resulting land-use and public health metrics are far from sustainable. However, single-objective models focusing on public health or land-use are inefficient and they deteriorate the metrics outside the objective. This further motivates the multiobjective approach studied in this paper, where a model is proposed to minimize the deviation of each criterion from its optimal target. The best tradeoff between the metrics is indeed achieved when all dimensions are considered simultaneously.

The scope of this work, together with an increasing push for a wide-range research focus on sustainability, provides several interesting further extensions. Integrated modeling approaches should be developed to simultaneously consider interrelated supply chain decisions, as demonstrated by Mota and et al. [41]. To this aim, optimization models can be developed to incorporate facility location decisions with other decisions, such as waste collection schemes, transport modes, and disposal technologies. This will require developing and solving complex multiobjective location-routing problems. Another line of research should focus on incorporating uncertainty into the problem. It is clearly of interest to investigate the extent to which the problem's features such as the amount of waste, the transportation costs, and their inherent uncertainties can impact sustainability metrics and costs. Finally, given the complexity of the current model and its possible extensions, a further research direction should focus on the development of efficient solution algorithms to obtain good solutions on large realistic networks.

\section{Data Availability}

The data used to support the findings of this study are available from the corresponding author upon request.

\section{Conflicts of Interest}

The authors declare that there are no conflicts of interest regarding the publication of this paper.

\section{References}

[1] L. Bastin and D. M. Longden, "Comparing transport emissions and impacts for energy recovery from domestic waste (EfW): Centralised and distributed disposal options for two UK counties," Computers, Environment and Urban Systems, vol. 33, no. 6, pp. 492-503, 2009.
[2] F. Ncube, E. J. Ncube, and K. Voyi, "A systematic critical review of epidemiological studies on public health concerns of municipal solid waste handling," Perspectives in Public Health, vol. 137, no. 2, pp. 102-108, 2016.

[3] L. A. Nwaogu, C. O. Ujowundu, C. I. Iheme, T. N. Ezejiofor, and D. C. Belonwu, "Effect of sublethal concentration of heavy metal contamination on soil physicochemical properties, catalase and dehydrogenase activities," International Journal of Biochemistry Research \& Review, vol. 4, no. 2, pp. 141-149, 2014.

[4] G. Owusu, E. Nketiah-Amponsah, S. N. A. Codjoe, and R. L. Afutu-Kotey, "How do Ghanas landfills affect residential property values? A case study of two sites in Accra," Urban Geography, vol. 35, no. 8, pp. 1140-1155, 2014.

[5] V. Spoann, T. Fujiwara, B. Seng, and C. Lay, "Municipal solid waste management: Constraints and opportunities to improve capacity of local government authorities of Phnom Penh Capital," Waste Management \& Research, vol. 36, no. 10, pp. 985-992, 2018.

[6] G. Owusu, "Social effects of poor sanitation and waste management on poor urban communities: a neighborhood-specific study of Sabon Zongo, Accra," Journal of Urbanism, vol. 3, no. 2, pp. 145-160, 2010.

[7] V. Ibáñez-Forés, M. D. Bovea, C. Coutinho-Nóbrega, and H. R. de Medeiros, "Assessing the social performance of municipal solid waste management systems in developing countries: Proposal of indicators and a case study," Ecological Indicators, vol. 98, pp. 164-178, 2019.

[8] P. Ferrão, P. Ribeiro, J. Rodrigues et al., "Environmental, economic and social costs and benefits of a packaging waste management system: a portuguese case study," Resources, Conservation \& Recycling, vol. 85, pp. 67-78, 2014.

[9] H. Yuan, "A model for evaluating the social performance of construction waste management," Waste Management, vol. 32, no. 6, pp. 1218-1228, 2012.

[10] H. Ak and W. Braida, "Sustainable municipal solid waste management decision making: Development and implementation of a single score sustainability index," Management of Environmental Quality: An International Journal, vol. 26, no. 6, pp. 909-928, 2015.

[11] J. L. Moura, A. Ibeas, and L. dell'Olio, "Optimization-simulation model for planning supply transport to large infrastructure public works located in congested urban areas," Networks and Spatial Economics, vol. 10, no. 4, pp. 487-507, 2010.

[12] E. M. Ferguson, J. Duthie, A. Unnikrishnan, and S. T. Waller, "Incorporating equity into the transit frequency-setting problem," Transportation Research Part A: Policy and Practice, vol. 46, no. 1, pp. 190-199, 2012.

[13] H. R. Jafari, M. Seifbarghy, and M. Omidvari, "Sustainable supply chain design with water environmental impacts and justice-oriented employment considerations: a case study in textile industry," Scientia Iranica, vol. 24, no. 4, pp. 2119-2137, 2017.

[14] K. Manaugh, M. G. Badami, and A. M. El-Geneidy, "Integrating social equity into urban transportation planning: a critical evaluation of equity objectives and measures in transportation plans in north america," Transport Policy, vol. 37, pp. 167-176, 2015.

[15] M. O. Beiler and M. Mohammed, "Exploring transportation equity: Development and application of a transportation justice framework," Transportation Research Part D: Transport and Environment, vol. 47, pp. 285-298, 2016. 
[16] A. Bernstad Saraiva, R. G. Souza, C. F. Mahler, and R. A. B. Valle, "Consequential lifecycle modelling of solid waste management systems - Reviewing choices and exploring their consequences," Journal of Cleaner Production, vol. 202, pp. 488-496, 2018.

[17] A. P. Rodrigues, M. L. Fernandes, M. F. F. Rodrigues, S. C. Bortoluzzi, S. E. Gouvea da Costa, and E. Pinheiro de Lima, "Developing criteria for performance assessment in municipal solid waste management," Journal of Cleaner Production, vol. 186, pp. 748-757, 2018.

[18] Y. M. Zhang, G. H. Huang, and L. He, "An inexact reverse logistics model for municipal solid waste management systems," Journal of Environmental Management, vol. 92, no. 3, pp. 522530, 2011.

[19] E. A. Toso and D. Alem, "Effective location models for sorting recyclables in public management," European Journal of Operational Research, vol. 234, no. 3, pp. 839-860, 2014.

[20] D. Inghels, W. Dullaert, and D. Vigo, "A service network design model for multimodal municipal solid waste transport," European Journal of Operational Research, vol. 254, no. 1, pp. 6879, 2016.

[21] Z. Xu, A. Elomri, S. Pokharel, Q. Zhang, X. G. Ming, and W. Liu, "Global reverse supply chain design for solid waste recycling under uncertainties and carbon emission constraint," Waste Management, vol. 64, pp. 358-370, 2017.

[22] M. Eskandarpour, P. Dejax, J. Miemczyk, and O. Péton, "Sustainable supply chain network design: An optimizationoriented review," OMEGA - The International Journal of Management Science, vol. 54, pp. 11-32, 2015.

[23] H. Khandelwal, H. Dhar, A. K. Thalla, and S. Kumar, "Application of life cycle assessment in municipal solid waste management: a worldwide critical review," Journal of Cleaner Production, vol. 209, pp. 630-654, 2019.

[24] P. Yadav and S. R. Samadder, "A critical review of the life cycle assessment studies on solid waste management in Asian countries," Journal of Cleaner Production, vol. 185, pp. 492-515, 2018.

[25] N. S. Kubanza, D. K. Das, and D. Simatele, "Some happy, others sad: exploring environmental justice in solid waste management in kinshasa, the democratic republic of congo," Local Environment, vol. 22, no. 5, pp. 595-620, 2017.

[26] N. S. Kubanza and D. Simatele, "Social and environmental injustices in solid waste management in sub-saharan africa: a study of kinshasa, the democratic republic of congo," Local Environment, vol. 21, no. 7, pp. 866-882, 2016.

[27] N. S. Kubanza and D. Simatele, "Sustainable solid waste management in sub-Saharan African cities: application of system thinking and system dynamic as methodological imperatives in kinshasa, the democratic republic of congo," Local Environment, vol. 23, no. 2, pp. 220-238, 2018.

[28] K. Kelobonye, G. McCarney, J. C. Xia, M. S. H. Swapan, F. Mao, and H. Zhou, "Relative accessibility analysis for key land uses: a spatial equity perspective," Journal of Transport Geography, vol. 75, pp. 82-93, 2019.

[29] J. Njeru, "The urban political ecology of plastic bag waste problem in Nairobi, Kenya," Geoforum, vol. 37, no. 6, pp. 10461058, 2006.

[30] J. Agyeman and T. Evans, "Toward just sustainability in urban communities: building equity rights with sustainable solutions," Annals of the American Academy of Political and Social Science, vol. 590, no. 1, pp. 35-53, 2003.

[31] J. M. Norton, S. Wing, H. J. Lipscomb, J. S. Kaufman, S. W. Marshall, and A. J. Cravey, "Race, wealth, and solid waste facilities in North Carolina," Environmental Health Perspectives, vol. 115, no. 9, pp. 1344-1350, 2007.

[32] C. J. L. Murray, "Quantifying the burden of disease: the technical basis for disability-adjusted life years," Bulletin of the World Health Organization, vol. 72, no. 3, pp. 429-445, 1994.

[33] M. Goedkoop, R. Heijungs, M. Huijbregts, A. De Schryver, J. V. Z. R. Struijs, and R. V. Zelm, "ReCiPe 2008, A life cycle impact assessment method which comprises harmonised category indicators at the midpoint and the endpoint level," First edition Report I: Characterisation, 2009, http://www.lcia-recipe.net.

[34] L. M. I. Canals, C. Bauer, J. Depestele et al., "Key elements in a framework for land use impact assessment within LCA," The International Journal of Life Cycle Assessment, vol. 12, no. 1, pp. 5-15, 2007.

[35] T. Koellner, L. De Baan, T. Beck et al., "UNEP-SETAC guideline on global land use impact assessment on biodiversity and ecosystem services in LCA," The International Journal of Life Cycle Assessment, vol. 18, no. 6, pp. 1188-1202, 2013.

[36] PCD, "Solid waste of community management in 2016," Pollution Control Department Report, Pollution Control Department Thailand, 2016.

[37] B. Gouge, H. Dowlatabadi, and F. J. Ries, "Minimizing the health and climate impacts of emissions from heavy-duty public transportation bus fleets through operational optimization," Environmental Science \& Technology, vol. 47, no. 8, pp. 37343742, 2013.

[38] S. L. Greco, A. M. Wilson, J. D. Spengler, and J. I. Levy, "Spatial patterns of mobile source particulate matter emissionsto-exposure relationships across the United States," Atmospheric Environment, vol. 41, no. 5, pp. 1011-1025, 2007.

[39] S. Olapiriyakul, "Designing a sustainable municipal solid waste management system in Pathum Thani, Thailand," International Journal of Environmental Technology and Management, vol. 20, no. 1-2, pp. 37-59, 2017.

[40] W. Kachapanya, Sustainable solid waste management system in urban areas of Pathum Thani Thailand. (Master of Science; Management Mathematics), Sirindhorn International Institute of Technology, Thammasat University, 2018, https://drive.google .com/drive/folders/14Okc0vUmjCHbgkBCdqLbPR1Gy7lDVaVg.

[41] B. Mota, M. I. Gomes, A. Carvalho, and A. P. Barbosa-Povoa, "Sustainable supply chains: An integrated modeling approach under uncertainty," OMEGA - The International Journal of Management Science, vol. 77, pp. 32-57, 2018. 


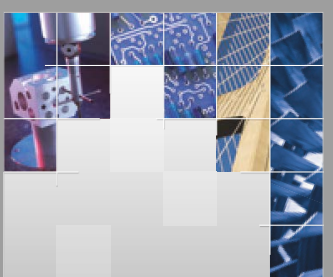

\section{Enfincering}
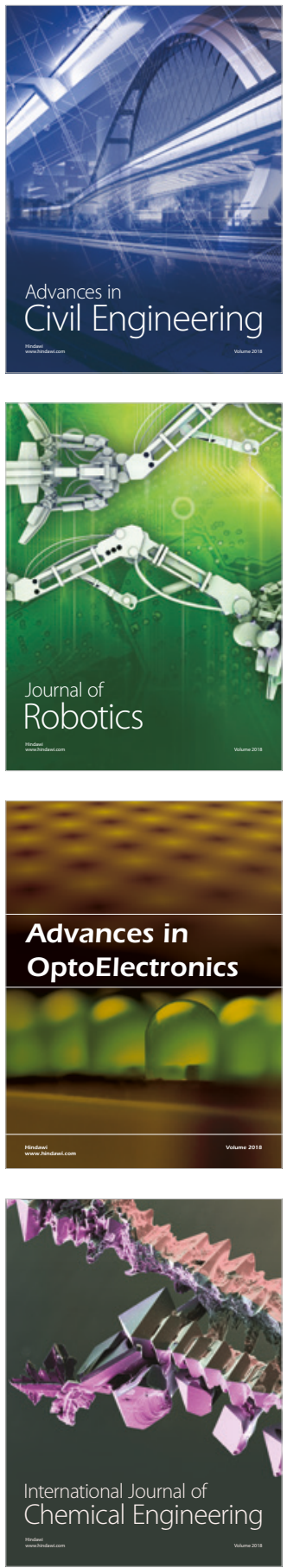

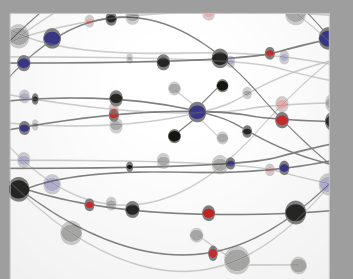

\section{Rotating \\ Machinery}

The Scientific World Journal

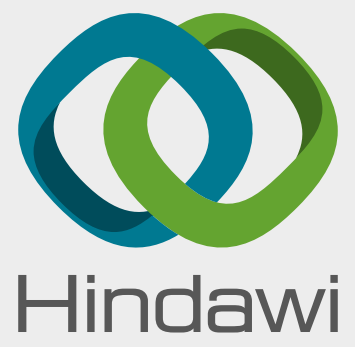

Submit your manuscripts at

www.hindawi.com
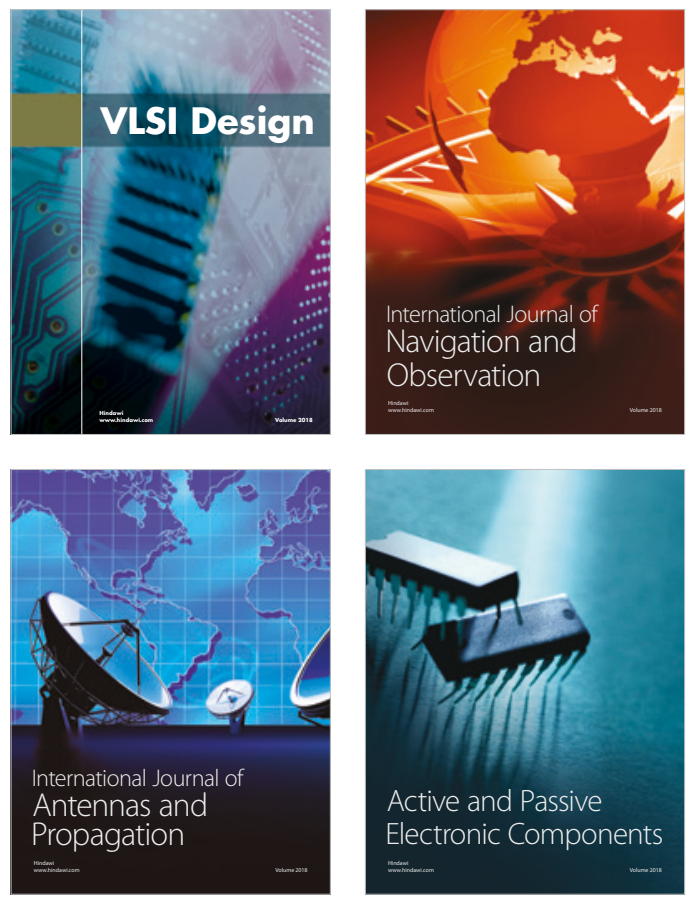
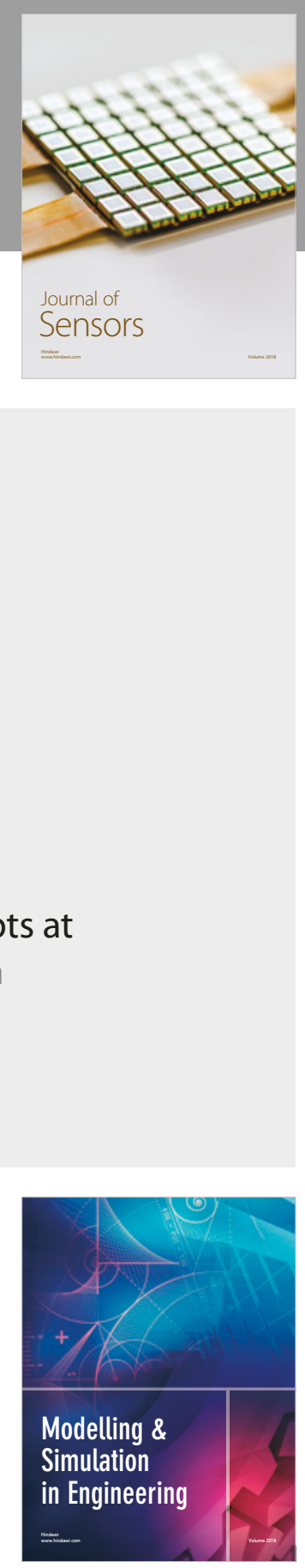

\section{Advances \\ Multimedia}
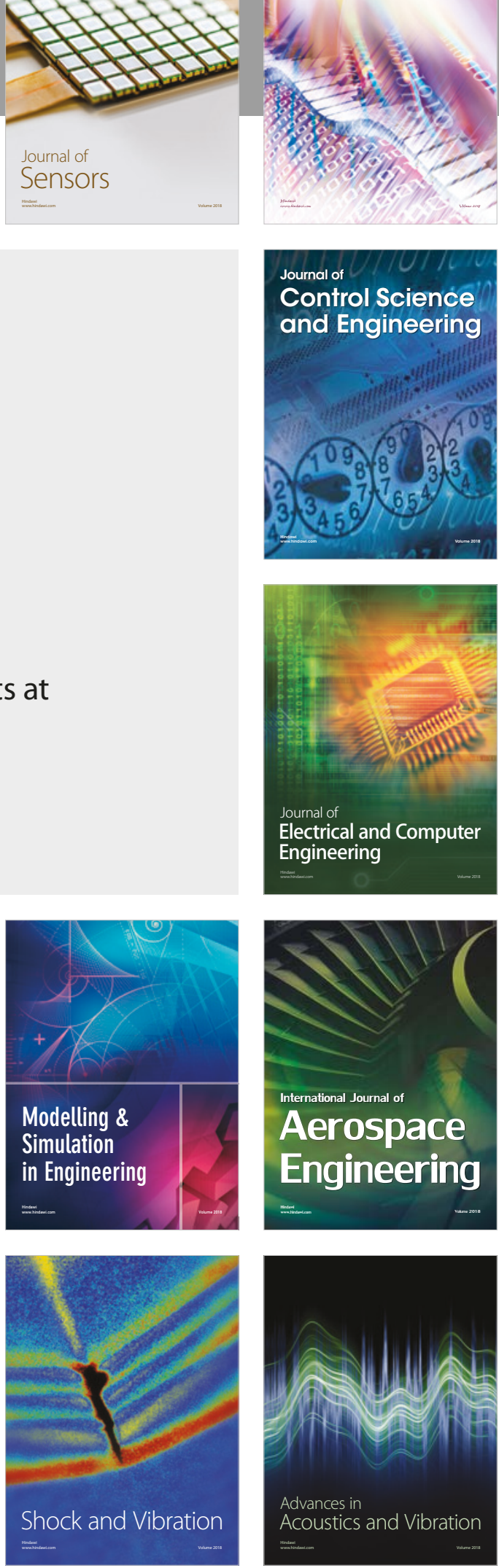